\title{
BIOCHEMICAL STUDIES ON VERTICAL TRANSMISSION OF A TOXOPLASMA CIRCULATING ANTIGEN
}

\author{
${ }^{1}$ Attallah A.M., ${ }^{1}$ EL-Mouayed M.A. and ${ }^{2}$ EI-Waseef AM. \\ ${ }^{1}$ R\&D Dept., Biotechnology Research Center, New \\ Damietta City, Egypt ${ }^{2}$ Chemistry Dept., Faculty of \\ Science,Mansoura Universty, Egypt.
}

\begin{abstract}
The detection of toxoplasma-specific antibodies is the primary diagnostic method to determine infection with toxoplasma in pregnant women. The present study aimed to evaluate the vertical transmission of anti-Toxoplasma gondii antibodies (IgM, IgG). ELISA is one of the easiest tests and most helpful technique in the diagnosis of toxoplasmosis. The $36 \mathrm{kDa}$ toxoplasma gondii(T.gondi) circulating antigen was isolated and purified from serum of toxoplasma infected mothers and umbilical cord samples of their neonates by electroelution. This antigen was used to detect the antiT.gondii IgM and IgG antibodies in 95 serum samples from pregnant mothers and 95 umbilical cord samples collected from the umbilical cord of their neonates. Total anti-T.gondii IgM antibodies were detected in 32 (33.7\%) serum samples with vertical transmission rate (9.4\%). Total anti-T.gondii IgG antibodies were detected in 26 (27.4\%) serum samples with vertical transmission rate (53.8\%). The serodiagnosis of toxoplasmosis based on the detection of antibodies is not useful for the detection of toxoplasma vertical transmission. However, T.gondii circulating antigen was detected in 55 (58\%) serum samples with vertical transmission rate $(81.8 \%)$ in respect to antigen positive. Therefore, the detection of T.gondii circulating antigen in umbilical cord serum is considered as a good evidence for vertical transmission of this antigen.
\end{abstract}




\section{INTRODUCTION}

Toxoplasma gondii (T.gondii) is an intracellular parasite that frequently infects a large spectrum of warm-blooded animals ${ }^{(1)}$. Infections with Toxoplasma gondii occur worldwide, but are especially prevalent in Europe, South America and Africa ${ }^{(2)}$. The main infection routes are ingestion of cysts from raw or badly-cooked meat, ingestion of oocysts from substrates contaminated with the feces of infected felines and congenital transmission by tachyzoites (3). The definitive host of $T$. gondii is the cat, but the parasite can be carried by the vast majority of warm-blooded animals, including humans ${ }^{(4)}$. T. gondii is the cause of toxoplasmosis which is usually asymptomatic in an immunocompetent person but can have serious or even fatal effects on a fetus whose mother first contracts the disease during pregnancy or on an immunocompromised human ${ }^{(5)}$. In pregnancy, primary infection of the mother may lead to vertical transmission, followed by fetal infection which presents the risk of congenital abnormalities. Toxoplasmosis in pregnant mothers is diagnosed in the laboratory based on immunological testing that gives the titer of circulating antibodies, detection of the relevant antibody classes at each phase of the illness, isolation of the parasite, polymerase chain reaction (PCR), circulating antigen investigation and ultrasound imaging ${ }^{(6)}$. Acute and latent $T$. gondii infections during pregnancy are mostly diagnosed by serological tests including detection of anti-T.gondii-specific IgM and $\operatorname{IgG}$ antibodies ${ }^{(5)}$ since, the serologic methods are simple and inexpensive ${ }^{(7)}$. The aim of the present study was to determine the vertical transmission rates of antitoxoplasma gondii antibodies and circulating toxoplasma gondii antigen.

\section{SUBJECTS AND MRTHODS}

A total of 95 serum samples from pregnant mothers were included in the present study and umbilical cord samples were collected from the umbilical cord of their neonates at delivery. Serum 
samples from 31 healthy controls were included, as a negative control group.

\section{Toxoplasma gondii antigen identification and purification}

Serum samples from random pregnant women and cord samples of their neonates were resolved using SDS-PAGE according to the method of ${ }^{(8)}$, then electro-transferred onto nitrocellulose membrane (NC) according to the method of ${ }^{(9)}$. The NC membrane was blocked using $3 \%(\mathrm{w} / \mathrm{v})$ bovine serum albumin (BSA) dissolved in $0.05 \% \mathrm{M}$ Tris-buffered saline (TBS), containing $200 \mathrm{mM} \mathrm{NaCl}(\mathrm{pH}$ 7.4), rinsed in TBS, and incubated with specific polyclonal antibodies to toxoplasma gondii antigen $(1: 75)$ in $1 \%$ BSA dissolved in TBS with constant shaking. The NC membrane was washed three times, 15 min each, in TBS followed by incubation separately for $2 \mathrm{~h}$ with antirabbit IgG alkaline phosphates conjugate (Sigma) diluted 1: 50 in TBS. After washing 3 times with TBS (15 min each), the NC membrane was exposed to alkaline phosphates substrate [5-bromo-4chloro-3-indolyl phosphate] (BCIP)/ nitroblue tetrazolium (NBT) in $0.1 \mathrm{M}$ Tris buffer, $\mathrm{pH} 9.6$ [Sigma] for $10 \mathrm{~min}$ and the reaction was stopped using distilled water. The specific band of target antigen appeared at $36 \mathrm{kDa}$.

\section{Gel electroelution}

The target toxoplasma antigen band $(36-\mathrm{kDa})$ was cut and electroeluted from preparative polyacrylamide gels at 200 volts for $4 \mathrm{~h}$ in a dialysis bag (Sigma). After dialysis, the electroeluted antigen band was concentrated using polyethylene glycol and $40 \%$ trichloroacetic acid, then centrifuged at $6500 \times \mathrm{g}$ for $15 \mathrm{~min}$. The precipitate was washed twice using diethyl ether. The excess diethyl ether was removed by gentle drying and the pellet was reconstituted in phosphate buffered saline (PBS), $\mathrm{pH}$ 7.2. The protein content of the purified toxoplasma antigen band was determined according to the method of ${ }^{(10)}$ before remainder was stored at $-20{ }^{\circ} \mathrm{C}$. 


\section{Detection of IgM and IgG antibodies using ELISA.}

After optimization of the reaction conditions, flat-bottomed polystyrene, micro-titer plates (Corning Life Sciences, Acton, MA) were coated with the purified $36 \mathrm{kDa}$ Toxoplasma gondii antigen (150 $\mu \mathrm{g} /$ well). After blocking, $50 \mu \mathrm{l} /$ well serum samples of pregnant women and cord samples of their neonates were added with dilution of 1:250 for IgM antibodies and 1:1000 for IgG antibodies, in PBS with $0.05 \%(\mathrm{v} / \mathrm{v})$ Tween 20 (PBS-T20). The plates were incubated at $37^{\circ} \mathrm{C}$ for 2 hours, washed, and then incubated with anti-human IgM or IgG alkaline phosphates conjugate (The Binding Site, Bermingham, UK.) with dilution $1: 500$ or $1: 1000$ in $0.2 \%(w t / v)$ BSA in PBS-T20. After washing, the substrate was added and the plates were incubated for $30 \mathrm{~min}$ at $37^{\circ} \mathrm{C}$. Optical densities (O.D) were read at $490 \mathrm{~nm}$ using a micro-plate auto-reader (Metertech Inc. USA). The cut-off O.D for ELISA positivity was set as mean O.D plus three S.D. for the sera from healthy individuals.

\section{Detection of T.gondii antigen using ELISA.}

The surface of polystyrene microtitre plates was coated with diluted serum samples (1:400) in coating buffer ( $\mathrm{pH}$ 9.6). After blocking, $50 \mu \mathrm{l} /$ well of specific polyclonal antibody diluted in $100 \mu \mathrm{l}$ of PBS-T2 0 were added, and then incubated at $37^{\circ} \mathrm{C}$ for 2 hours. 50 $\mu 1 /$ well of secondary antibody labeled enzyme (anti-rabbit) with dilution 1:800 in $0.2 \%(\mathrm{wt} / \mathrm{v})$ BSA in PBS-T20 were added, then the plates were incubated for $1 \mathrm{hr}$. After washing, the substrate was added and the plates were incubated for $30 \mathrm{~min}$ at $37^{\circ} \mathrm{C}$. Optical densities (O.D) were read at $490 \mathrm{~nm}$ using a micro-plate auto-reader (Metertech Inc. USA). The cut-off O.D for ELISA positivity was set as mean O.D plus three S.D. for the sera from healthy individuals.

\section{RESULTS}

\section{Detection of anti-toxoplasma gondii IgM and anti- toxoplasma IgG antibodies using ELISA.}


Serum from 95 pregnant mothers and cord samples were tested by ELISA technique for detection of the anti-toxoplasma gondii IgM, anti-toxoplasma gondii $\mathrm{IgG}$ antibodies and toxoplasma circulating antigen. Anti-toxoplasma gondii IgM antibodies were detected in 32 out of 95 serum samples $(33.7 \%)$, while they were not detected in the other $63(66.3 \%)$ serum samples (Figure 1). Antitoxoplasma IgG antibodies were detected in 26 out of 95 serum samples $(27.4 \%)$, while they were not detected in the other 69 $(72.6 \%)$ serum samples (Figure 1). Toxoplasma gondii antigen was detected in 55 out of 95 serum samples (58\%) serum samples of total 95 samples, while 40 out of 95 serum samples (42\%) were negative and 45 out of 95 cord samples were positive for toxoplasma antigen (Figure 2).

The vertical transmission rates of anti-toxoplasma IgM, IgG antibodies and toxoplasma antigen from infected pregnant mothers to their neonates were detected using ELISA technique. Three out of 32 positive $\operatorname{IgM}$ mothers $(9.4 \%)$ were positive for anti-T.gondii IgM antibodies, while 14 out of 26 positive $\operatorname{IgG}$ mothers $(53.8 \%)$ were positive for anti-toxoplasma IgG antibodies and 45 out of 55 infected mothers $(81.8 \%)$. were positive for toxoplasma antigen (Figure 3). By using statistical analysis we found no significant correlation $(\mathrm{r}=$ $0.067, \mathrm{P}=0.297$ ) between the levels of anti-toxoplasma $\operatorname{IgM}$ antibodies (O.D) in mothers and their neonates (Figure 4), while a significant correlation $(\mathrm{r}=0.371, \mathrm{P}=0.0001)$ between the levels of anti-toxoplasma IgG in mothers and their neonates was found (Figure 5). A significant correlation was found between levels of toxoplasma circulating antigen in serum from pregnant mothers and cord samples from their neonates $(\mathrm{r}=0.562, \mathrm{P}=0.0001)$ (Figure 6). There was no significant correlation between levels of toxoplasma circulating antigen and levels of anti-toxoplasma IgM antibodies in cord samples $(\mathrm{r}=-0.06, \mathrm{P}=0.281)$ (Figure 7) while, a significant correlation was found between levels of toxoplasma circulating antigen and levels of anti-toxoplasma $\mathrm{IgG}$ antibodies in cord samples $(\mathrm{r}=0.197, \mathrm{P}=0.028)$ (Figure 8). 
BIOCHEMICAL STUDIES...

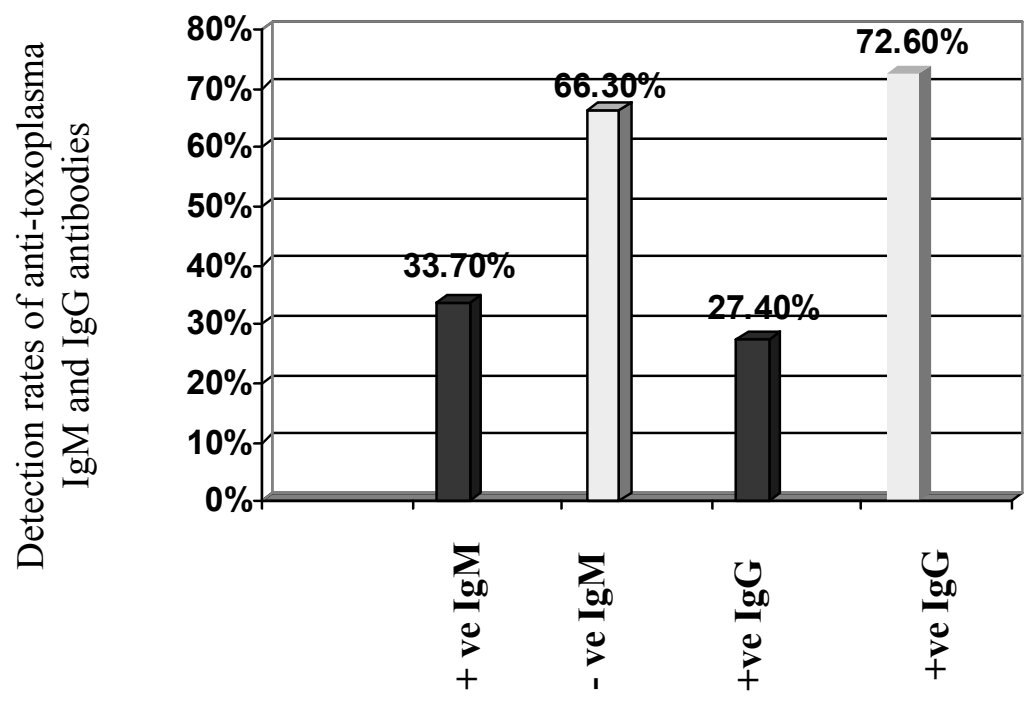

Fig. (1). Detection rates of anti-toxoplasma $\operatorname{IgM}$ and $\operatorname{IgG}$ antibodies in serum samples of pregnant mothers.

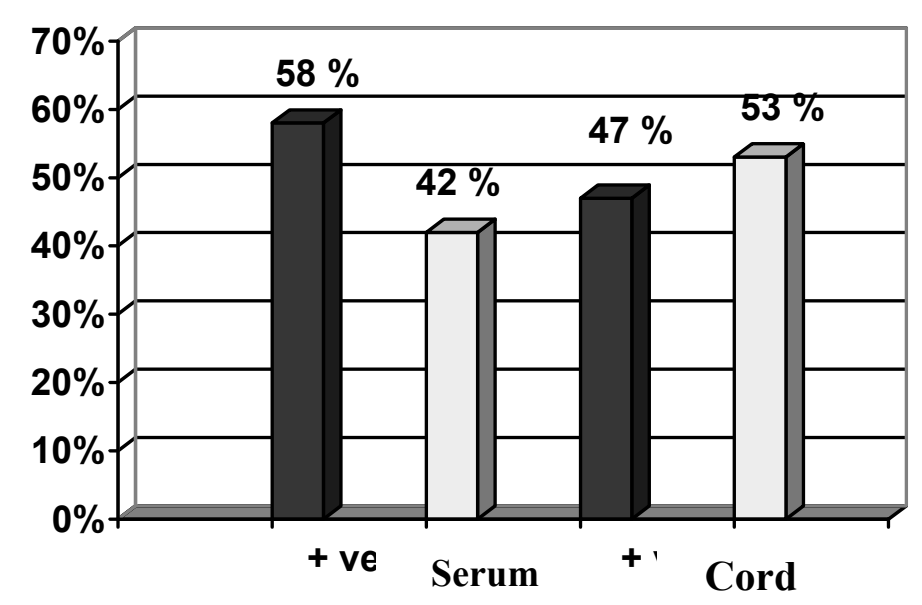

Fig. (2). Detection rates of toxoplasma antigen in serum samples of pregnant mothers and cord samples of their neonates. 
Attallah A.M. et al.

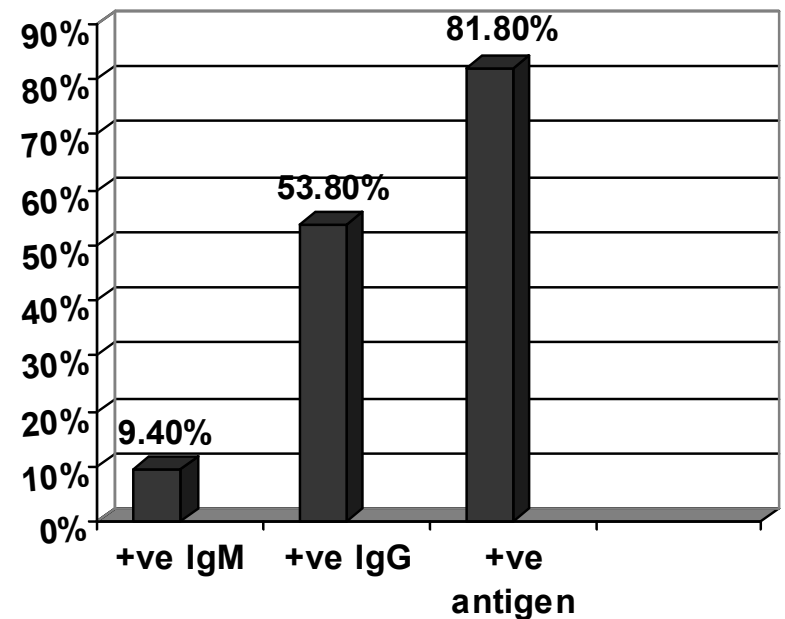

Fig. (3). Vertical transmission rates of anti-toxoplasma $\operatorname{IgM}, \operatorname{IgG}$ antibodies and toxoplasma antigen from infected mothers to their neonates via cord.

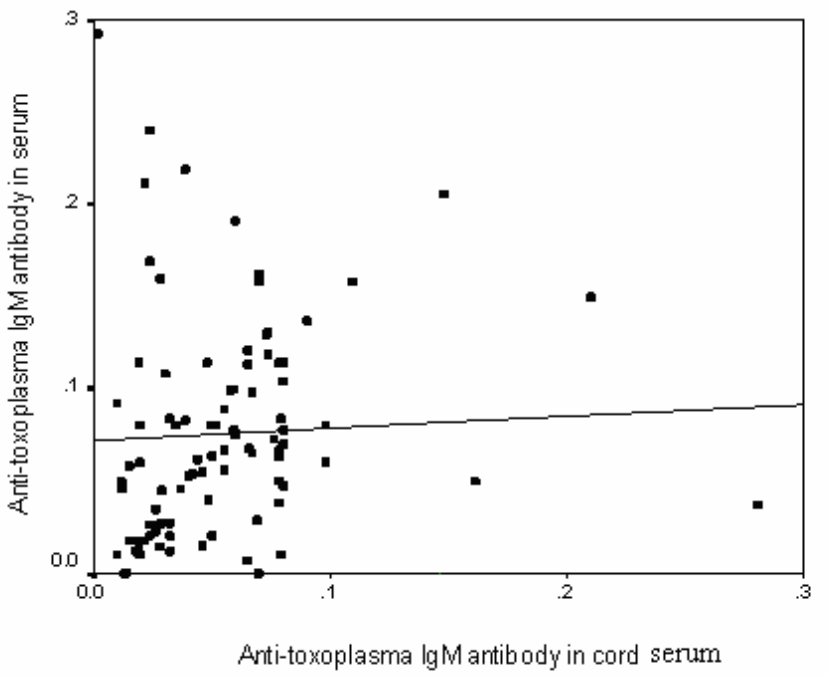

Fig. (4). Correlation between levels of anti-toxoplasma IgM antibodies in 95 serum and cord samples, $(r=0.067, P=0.297)$. 


\section{BIOCHEMICAL STUDIES...}

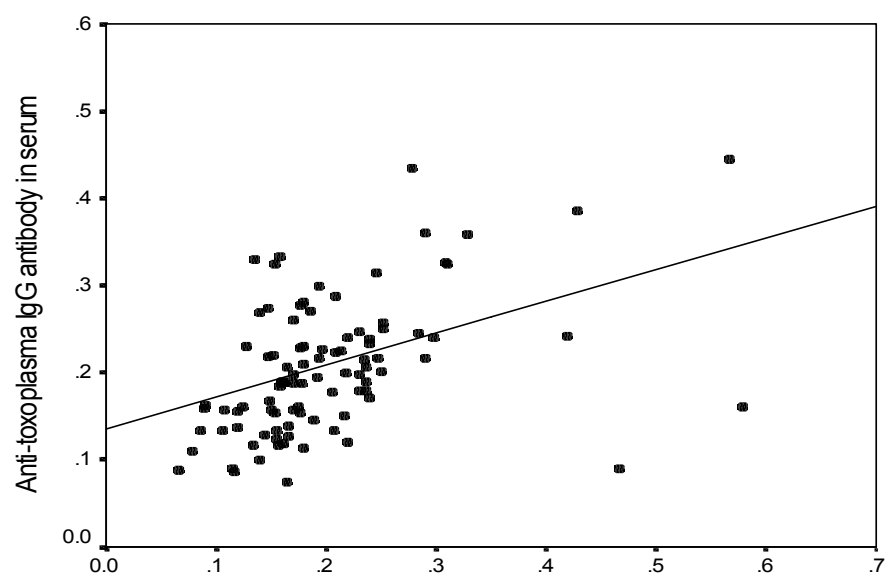

Anti-toxoplasma IgG antibody in cord serum

Fig. (5). Correlation between levels of anti-toxoplasma IgG antibodies in 95 serum and cord samples, $(\mathrm{r}=0.371, \mathrm{P}=0.0001)$.

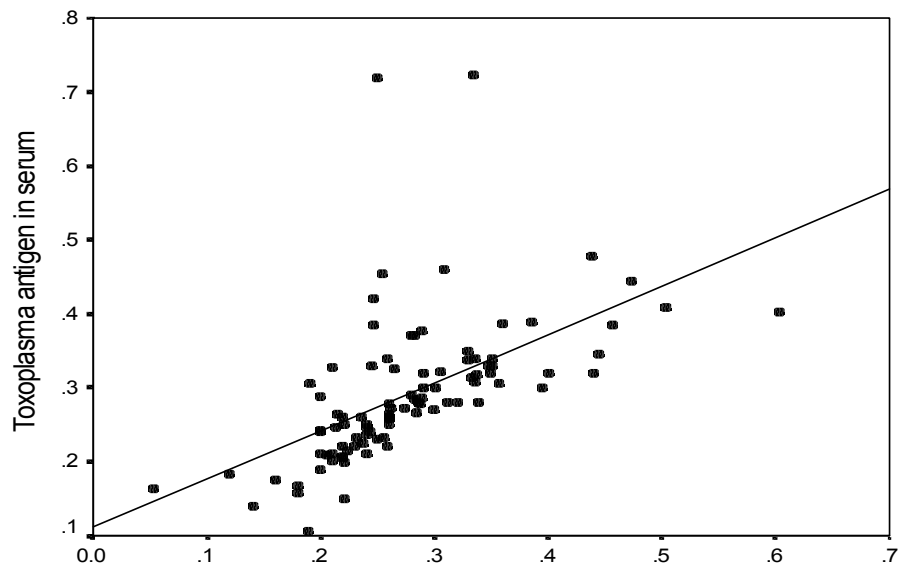

Toxoplasma antigen in cord serum

Fig. (6). Correlation between levels of toxoplasma antigen in serum from mothers and umbilical cord samples from their neonates, $(\mathrm{r}=0.562, \mathrm{P}=0.0001)$. 
Attallah A.M. et al.

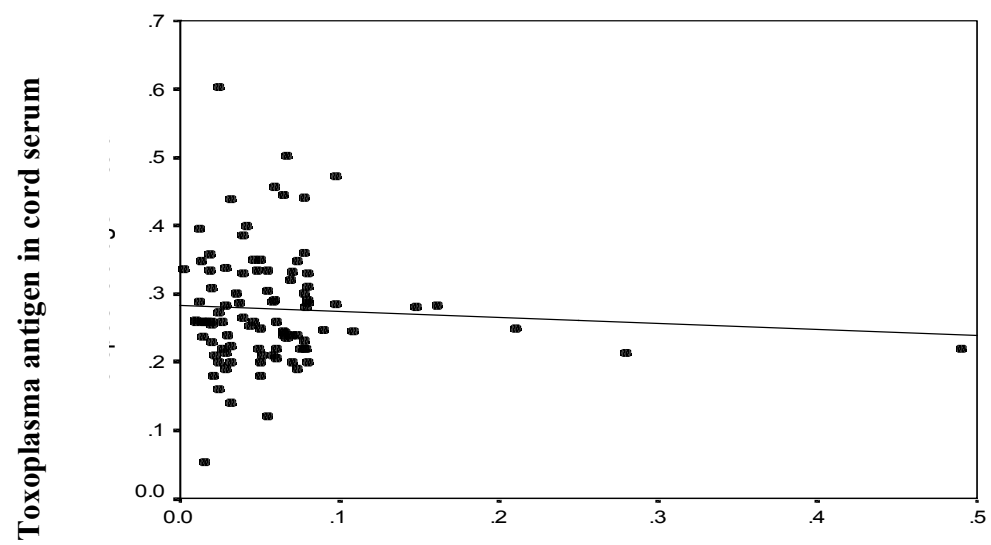

Anti- toxoplasma igM antibody in cord serum

Fig. (7). Correlation between levels of toxoplasma circulating antigen and anti-toxoplasma IgM antibodies in umbilical cord, ( $\mathrm{r}=-$ $0.06, \mathrm{P}=0.281$ ).

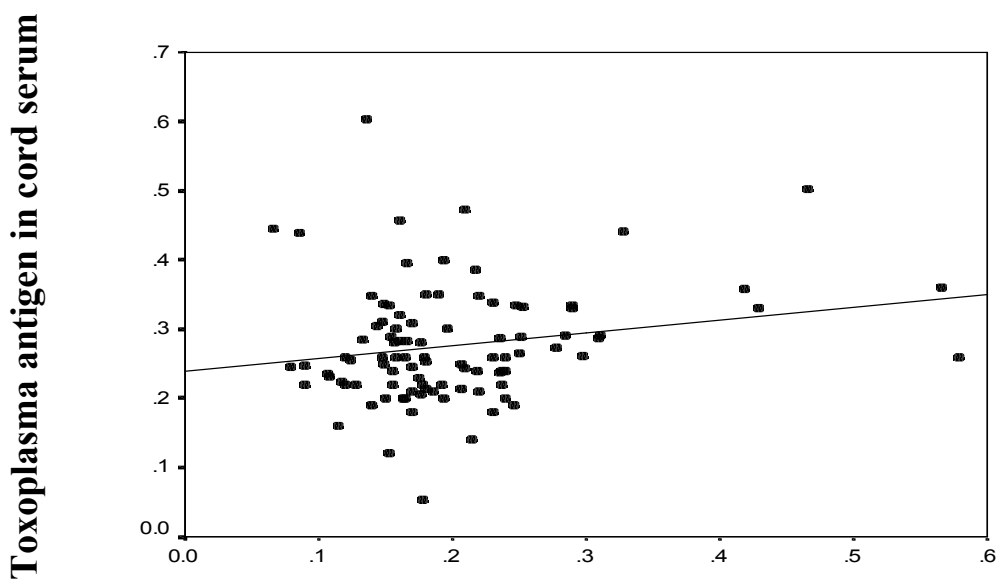

Anti- toxoplasma IgG antibodv in cord serum

Fig. (8). Correlation between levels of serum toxoplasma circulating antigen and anti-toxoplasma $\mathrm{IgG}$ antibodies in cord serum $\quad(r=0.197, \mathrm{P}=0.028)$. 


\section{DISCUSSION}

Toxoplasmosis in pregnant mothers can be diagnosed by following the titer of circulating antibodies, detection of the relevant antibody classes, isolation of the parasite, PCR and investigation of the circulating antigens ${ }^{(6)}$.The diagnosis by PCR is a quite timeconsuming and do not provide quantitative data (11). Histological diagnosis should not be made unless organisms with the typical structure are seen, as degenerating host cells may resemble degenerating $T$ gondii parasites ${ }^{(12)}$ and isolation of T.gondii method usually requires several days to obtain results ${ }^{(13)}$. The serologic methods are simple and inexpensive to perform and can differentiate between recently acquired and chronic toxoplasma infections in a single serum sample ${ }^{(7)}$.The detection of anti-toxoplasma antibodies by ELISA methods is commonly performed in many medical centers; the results of such tests are generally well accepted by clinicians because of their excellent sensitivities and specificities, the rapid availability of results, and the relatively low costs of the tests ${ }^{(14)}$. Toxoplasma immunoglobulins $\operatorname{IgM}$ and $\operatorname{IgG}$ are essential for the diagnosis of Toxoplasma infection in pregnant women ${ }^{(15)}$. The prevalence of anti-toxoplasma gondii $\operatorname{IgM}$ and $\operatorname{IgG}$ antibodies in 59 serum samples of pregnant women was measured to detect the vertical transmission rate of these antibodies to their neonates via placenta. Anti-T.gondii IgM antibodies were detected in $32(33.7 \%)$ serum samples with low vertical transmission rate $(9.4 \%)$; the other 63 $(66.3 \%)$ samples were negative for IgM. There was a range from 20 to $38 \%$ of vertical transmission of anti-toxoplasma IgM antibodies detected by several authors El-Nawawy et al., ${ }^{(16)}$; Dar et al., ${ }^{(17)}$ and Hovanec-Burns et al., ${ }^{(18)}$. Since, the anti-toxoplasma IgM antibodies are produced by the neonate itself (i.e. they do not pass across the placenta) ${ }^{(19)}$, no statistically significant correlation $(\mathrm{r}=0.067, \mathrm{P}=0.297)$ was shown between the levels of anti-toxoplasma IgM antibodies in mothers and their neonates and the immunization of fetal blood may be due to contamination by maternal blood during the first few days after birth ${ }^{(20)}$. Anti-T.gondii IgG antibodies were detected in 26 $(27.4 \%)$ serum samples with vertical transmission rate $53.8 \%$ while 
the other 69 samples $(72.6 \%)$ were negative for $\mathrm{IgG}$. There was a very wide range from 9.3 to $100 \%$ of vertical transmission of antitoxoplasma IgG antibodies reported by several authors Yu, ${ }^{(21)}$; ElNawawy et al., (16) and Hovanec-Burns et al., ${ }^{(18)}$. Since, the maternal IgG antibodies cross the placental barrier and will appear and persist for several months in the circulation of the newborn ${ }^{(22)}$, a significant correlation $(\mathrm{r}=0.371, \mathrm{P}=0.0001)$ was shown between levels of anti-toxoplasma IgG antibodies in mothers and their neonates (Fig 5). Serodiagnosis of congenital infection depending on the presence of IgG antibodies in the sera of suspected fetuses is not helpful as it is difficult to differentiate between fetal $\mathrm{IgG}$ antibodies and maternal $\operatorname{IgG}$ antibodies that have migrated across the placenta ${ }^{(23)}$ .In contrast, the presence of anti-toxoplasmic IgM or IgA in the neonate is the most specific sign of congenital infection because these antibodies are produced by the neonate itself (i.e. they do not pass across the placenta). At the same time, the absence of IgM does not rule out acute congenital toxoplasmosis, because $\operatorname{IgM}$ antibodies can only be detected in about $20 \%$ of congenital infections ${ }^{(24)}$. T.gondii circulating antigen was detected in 55 serum samples (58\%) with high vertical transmission rate $(81.8 \%)$, the other 40 samples $(42 \%)$ were negative for T.gondii antigen. Different ranges of vertical transmission rates of toxoplasma antigen were reported by several authors Greco et al., ${ }^{(25)}$; Di Carlo et al., ${ }^{(26)}$ and Mazzola et al., ${ }^{(27)}$. No significant correlation $(\mathrm{r}=-0.06, \mathrm{P}=0.281)$ was found between levels of toxoplasma antigen and anti-toxoplasma $\operatorname{IgM}$ antibodies in cord samples. This may be attributed to the high molecular weight of these antibodies $60-\mathrm{kDa}$, Decoster et al., ${ }^{(28)}$.On the other hand a significant correlation $(\mathrm{r}=0.197, \mathrm{P}=0.028)$ was found between the levels of toxoplasma antigen and anti-toxoplasma $\operatorname{IgG}$ antibodies in cord samples and this is attributed to the small molecular weight of $\operatorname{IgG}$ antibody 12-kDa, Decoster et al., ${ }^{(28)}$. The present findings indicate that the detection of T.gondii circulating antigen appears to be a promising alternative approach for laboratory diagnosis of vertical transmission of T.gondii infection. 


\section{CONCLUSION}

The detection rate of vertical transmission of toxoplasma increased from $\operatorname{IgM}(9.4 \%)$, IgG antibodies (53.8\%) to toxoplasma circulating antigen $(81.8 \%)$, indicate the high sensitivity of T.gondii circulating antigen in early diagnosis of congenital toxoplasmosis which is a high evidence for vertical transmission of the disease.

\section{REFERENCES}

1. Buzoni-Gatel, D.; Dubremetz, J.F. and Werts, C. (2008): Molecular cross talk between Toxoplasma gondii and the host immune system. Med Sci (Paris). 24(2): 191-196.

2. Petersen, E. (2007): Toxoplasmosis. Semin Fetal Neonatal Med. 12(3): 214-223.

3. Lopes, F.M.; Gonçalves, D.D.; Mitsuka-Breganó, R.; Freire, R.L. and Navarro, I.T. (2007): Toxoplasma gondii infection in pregnancy._Braz J Infect Dis. 11(5): 496-506.

4. Dubey, J.P.; Beattie, C.P. and Boca Raton, F.L. (1988): Toxoplasmosis in man (Homo sapiens). In: Toxoplasmosis of Animals and Man. CRC Press, Inc. pp 41-60.

5. Montoya, J.G. and Liesenfeld, O. (2004): Toxoplasmosis. lancet 363(9425): 1965-1976.

6. Rorman, E.; Zamir, C.S.; Rilkis, I. and Ben-David, H. (2006):

Congenital toxoplasmosis - prenatal aspectos of Toxoplasma gondii infection. Reprod Toxicol. 21: 458-472.

7. Thulliez, P.; Remington, J. S.; Santoro, F.; Ovlaque, G.; Sharma, S. and Desmonts, $\boldsymbol{G}$. (1986): A new agglutination reaction for the diagnosis of the developmental stage of acquired toxoplasmosis. Pathol. Biol. (Paris). 34: 173-177. 
8. Laemmli, U.K. (1970): Cleavage of the structural proteins during the assembly of the deal of the bacterophage T4. Nature (London). 227: 680-685.

9. Towbin, H.; Stachlin, T. and Gordon, J. (1979): Electrophoretic transfer of protein from polyacrylamide gels to nitrocellulose sheets Procedure and some applications. Proc. Natl. Acad. Sci. 76: 4350.

10. Lowry, O.H.; Roenbrough, N.J.; Farr, A.L. and Randall, R.J. (1951): Protein measurement with folin-phenol reagent. J. Biol. Chem. 193: 265-275.

11. Das, H.; Koizumi, T.; Sugimoto, T.; Chakraborty, S.; Ichimura, T.; Hasegawa, K. and Nishimura, R. (2000): Quantitation of Fas and Fas ligand gene expression in human ovarian, cervical and endometrial carcinoma using real-time quantitative RTPCR. Br J Cancer. 82: 1682-1688.

12. Remington, J.S.; McLeod, R. and Desmonts, G. (1995): Toxoplasmosis. In: Infectious Disease of the Fetus and Newborn Infant.Remington, J.S. and Klein, J.O., (Eds.). 4th ed., W.B. Saunders Company. Philadelphia. pp 140-267.

13. Luft, B.J. and Remington, J.S. (1992): Toxoplasmic encephalitis in AIDS.Clin. Infect. Dis. 15: 211-222.

14. Liesenfeld, O.; Press, C.; Flanders, R.; Ramirez, R. and Remington, J.S. (1996): Study of Abbott Toxo IMx system for detection of immunoglobulin $\mathrm{G}$ and immunoglobulin $\mathrm{M}$ Toxoplasma antibodies: value of confirmatory testing for diagnosis of acute toxoplasmosis. J. Clin. Microbiol. 34: 25262530.

15. Al-Harthi, S.A.; Jamjoom Manal, B. and Hani, O. (2006): Ghazi Seroprevalence of Toxoplasma Gondii among Pregnant Women in Makkah, Saudi Arabia. J. Sci. Med. Eng., 18 (2): $217-227$.

16. El-Nawawy, A.; Soliman, A.T.; El Azzouni, O.; Karim, M.A.; Demian, $S$. and El Sayed, M. (1996): Maternal and neonatal prevalence of toxoplasma and cytomegalovirus (CMV) antibodies and hepatitis-B antigens in an Egyptian rural area. Egypt. J Trop Pediatr.42 (3): 154-157. 


\section{BIOCHEMICAL STUDIES...}

17. Dar, F.K.; Alkarmi, T.; Uduman, S.; Abdulrazzaq, Y.; Grundsell, H. and Hughes, P. (1997): Gestational and Neonatal Toxoplasmosis: Regional Seroprevalence in the United Arab Emirates. European Journal of Epidemiology. 13(5): 567-571.

18. Hovanec-Burns, D.; Cervantes, C.; Gerstenecker, B.; Soll, H-J.; Janitschke, J. and El Shami, A.S. (1998): Detection of Toxoplasma gondii-specific IgG by IMMULITE. In: Abstracts of the 98th General Meeting of the American Society for Microbiology. 17-21.

19. Arcavi, M. and Orfus, G. (1997): Diagnosis of toxoplasmosis by joint detection of immunglobulin $\mathrm{A}$ and immunglobulin $\mathrm{M}$. J.Clin.Microbiol. 35(6): 1450-1453.

20. Lebech, M.; Joynson, D. H. M.; Seitz, H. M.; Thulliez, P.; Gilbert, R. E.; Dutton, G. N.; Ovlisen, B. and Petersen, E. (1996): Classification system and case definitions of Toxoplasma gondii infection in immunocompetent pregnant women and their congenitally infected offspring. Eur J Clin Microbiol Infect Dis. 15: 799-804.

21. Yu, J.C. (1985): A seroepidemiological study on Toxoplasma gondii infection among pregnant women and neonates in Taiwan. J Formos Med Assoc. 84: 286-295.

22. Brown, H.W. and Neva, F.A. (1987): Basic Clinical Parasitology. 5th ed. Appleton- Century- Crofts. USA. P 50.

23. Clough, L.A. (1997): Should a diagnosis of reactivation toxoplasmosis be made on the basis of a change in serum IgG titer? The AIDS reader. 7: 83-88.

24. Lycke, E.; Carlberg, K. and Norrbcy, R. (1975): Interactions between Toxoplasma gondii and its host cells functionenhancing factor of Toxoplasma. Infect. Immun.11: 853-861.

25. Greco, P.; Vimercati, A.; Angelici, M.C.; Carbonara, S.; Doria, G.; Nappi, L.; Angarano, G. and Selvaggi, L. (2003): Toxoplasmosis in pregnancy is still an open subject. J Perinat Med. 31(1): 36-40.

26. Di Carlo, P.; Mazzola, A.; Romano, A.; Schimmenti, M.G.; Colicchia, P.; Bellipanni, P. and Titone, L. (2005): Postnatal follow-up of infants born to mothers with certain Toxoplasma 
Attallah A.M. et al.

gondii infection: evaluation of prenatal management. Infez Med. 13(2): 72-78.

27. Mazzola, A.; Casuccio, A.; Romano, A.; Schimmenti, M.G.; Titone, L. and Di Carlo, P. (2007): Diagnostic problems and postnatal follow-up in congenital toxoplasmosis. RNAS Civico Benfratelli, G. Di Cristina and M. Ascoli, Palermo, Italy. 59 (3): 207-213.

28. Decoster, A.; Darcy, F. and Capron, A. (1988): Recognition of Toxoplasma gondii excreted and secreted antigens by human sera from acquired and congenital toxoplasmosis: identification of markers of acute and chronic infection. Clin Exp Immunol. 73(3): 376-382. 